\section{ECONOMICS}

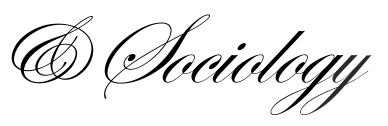

Asatiani, M., Verulava, T. (2017). Georgian Welfare State: Preliminary Study Based on Esping-Andersen's Typology. Economics and Sociology, 10(4), 21-28. doi:10.14254/2071-789X.2017/10-4/2

\title{
GEORGIAN WELFARE STATE: PRELIMINARY STUDY BASED ON ESPING-ANDERSEN'S TYPOLOGY
}

\author{
Magda Asatiani, \\ Ilia State University, \\ Tbilisi, Georgia, \\ E-mail: \\ magda.asatiani.1@iliauni.edu.ge \\ Tengiz Verulava, \\ Ilia State University, \\ Tbilisi, Georgia, \\ E-mail: \\ tengiz.verulava@iliauni.edu.ge \\ Received: March, 2017 \\ 1st Revision: June, 2017 \\ Accepted: October, 2017
}

DOI: $10.14254 / 2071-$

789X.2017/10-4/2

\section{JEL Classification: D60}

\begin{abstract}
This study aims to examine the welfare state of Georgia according to the Esping-Andersen's typology and to justify the theory of "(in)stable welfare states". This article analyses different aspects of wellbeing (pension and healthcare systems, labour-market policy and family benefits) in Georgia during the period of 1991-2013. The research shows the diversity of policies in different fields of social care. The results revealed that Georgian health and labour-market policies can be classified as liberal ones, while the pension system - as a social-democratic one, and finally the family benefits policy - as a conservative one. Thus, the theory of (in)stable welfare state can be justified in this case and Georgian state overall can be qualified as a country with a hybrid and instable social policy. However, further research is needed for the final confirmation (or rejection) of this theory, once the current policy reforms, started back in 2013, would be fully implemented.
\end{abstract}

Keywords: welfare state, Georgia, Esping-Andersen’s typology.

\section{Introduction}

Social policy is one of the most important components of any state policy, it focuses on those aspects of the economy, society and policy that are necessary to human existence and the means by which they can be provided. These basic human needs include: food and shelter, sustainable and safe environment, promotion of health and treatment of the sick, care and support for those unable to live a fully independent life; education and training of individuals to a level that enables them participate fully in the society's functioning (London School of Economics 2012).

The concept of welfare state was developed back in the $20^{\text {th }}$ century, and in it the state plays the key role when it comes to protection and promotion of economic and social wellbeing of citizens (Britannica Online Encyclopedia, 2013). The origins of collective welfare provision go back to Germany and the times just before the World War I. Otto von Bismarck introduced insurance schemes that shared risks of illness and accidents (Hague and Harrop, 2007). Even though the most contemporary welfare states are based on the ideas of Bismarck, overtime each country has developed its own type of welfare state.

Despite the differences and changes in welfare states ${ }^{6}$ development, researchers attempted to emphasize the social policy models and classify them. The Danish sociologist 
Gøsta Esping-Andersen in his work "The Three World of Welfare Capitalism" (1990) produced one of those typologies. This author proposed novel variables for determining the level of social wellbeing, such as: de-commodification index, social stratification and public-private nexus. He defined the de-commodification index as the extent to which individuals and families can afford an acceptable standard of living independently from market participation (EspingAndersen, 1990, p. 47). Social stratification captured through a wide range of indicators of how welfare state key institutions operate in structuring class and social order (Esping-Andersen, 1990 , p. 55). Under the concept of public-private nexus the author considered the relative roles of the state, the family and the market in welfare provision (Esping-Andersen, 1990, p. 65). Based on these variables Esping-Andersen distinguishes three types of welfare state: liberal or Anglo-Saxon, social-democratic or Nordic, and finally conservative or continental regimes.

Although this classification has been embraced by most of the scientific world, soon the debate about the typology offered by Esping-Andersen started. Among others, Ferrera (1996) and Bonoli (1997) paid attention to the so-called Southern European welfare states, such as in Greece, Spain and Italy. According to Esping-Andersen, these welfare states were to be considered as immature continental welfare states; however, some authors who criticized his work (e.g., Ferrara, 1996) disagree with this qualification and consider them as a specific, separate welfare type (Arts and Gelissen, 2002).

The next issue with this typology is that the classification was initially centered around Western-European countries (Burlacu, 2007). In other words, because the typology relied on the data from European countries mostly it was hard, if not impossible, to classify, for example, Eastern-European or South-East Asian states. Hence, relatively young welfare states like those in the post-Soviet countries (including Georgia) and some of the South-East Asian countries cannot be classified. Esping-Andersen rejected the idea of a new welfare state type, and stated that all these countries are in transition and can be allocated into one of the three original classes of welfare states after a certain number of years (Esping-Andersen, 1996). The author believed that eventually all welfare states will fit into one of the distinguished types.

Thus, Esping-Andersen argued that any hybrid welfare state that does not currently fit into one of the suggested types is instable, while only three described regimes of welfare state (liberal, social-democratic, conservative) are truly stable (Esping-Andersen,1996).

Taking into consideration the fact, that there is no study assessing Georgian welfare status (using any typology/classification), the indepth analysis of Georgian social policy is getting more challenging. Also, detailed exploration of a relatively new Georgian welfare state may justify or question this theory.

Hence, our central research question can be formulated as follows: To what extent does the welfare state of Georgia fit into the classification scheme of Esping-Andersen and how does this affect the Esping-Andersen's theory of (in)stable welfare states?

\section{Methodology}

This study aims to analyze whether the welfare state of Georgia is developing towards a welfare state which can be classified as one of Esping-Andersen's welfare regimes or towards a hybrid (instable) system which combines elements of these regimes. Many studies, starting from 1958 by Richard Tittmus to more recent ones (among others Clayton \& Pontusson, 1998; Fenger, 2007) focus on social spending of welfare states. This method of research has some limitations. Firstly, understanding the social expenditures requires a more in-depth analysis of how spending is actually directed (Esping-Andersen, 1990). Secondly, governments have other means for achieving social objectives beyond spending. A decrease in social spending might be due to the organizational changes that have improved efficiency and thus reduced social 
expenditures. Due to these limitations, in order to measure wellbeing in Georgia, the EspingAndersen approach was taken (1990).

In order to answer the research question, preliminary study was conducted; in particular, four aspects of the welfare state were analyzed. These are healthcare system, pension system, welfare state financing and family benefits. The period from 1991 (from the independence of Georgia) to 2013 (before the reforms of current government) was taken. Data were collected from secondary sources such as reports of the Social Service Agency of Georgia (SSA), the Organization for Economic Cooperation and Development (OECD), International Labour Organization (ILO), United States Agency for International Development (USAID) and also by an analysis of the literature concerning the development of Georgian welfare state.

The welfare state of Georgia was measured by specific criteria in order to fit certain development into one of Esping-Andersen's welfare types. These criteria are considered below. As described above, Esping-Andersen distinguishes three welfare types, namely the liberal, social-democratic and conservative type. The liberal welfare states are characterized by a limited government interference, privatization and focus on self-responsibility. Criteria used in this study in order to fit into the liberal welfare type are privatization, increasing selfresponsibility, decentralization and decreasing importance of the government or state. Thus, when a development of, for example, the health-care system of a country leans towards one or more of these criteria, it will fit into the liberal welfare type. The social-democratic welfare states are characterized by universal, Beveridge's welfare programs, generosity, guaranteed minimum incomes and a relative importance of the government. Hence, the criteria used in this study in order to fit the developments of the welfare state into the social-democratic welfare type are universal coverage, extensive and generous services and poverty reduction. Lastly, conservative welfare states are often characterized by Bismarckian, work-related welfare programs and means-tested services. The importance of the government can be described as medium. Criteria used in this study to fit developments of the analyzed welfare states in the conservative welfare type are work-related, protection of workers, means-tested and a medium important role of the government (Esping-Andersen, 1990). Table 1 below shows an overview of the criteria described above.

Table 1. Criteria for Welfare State Typology

\begin{tabular}{|c|c|c|}
\hline Liberal & Social-democratic & Conservative \\
\hline Privatization & Universal coverage & Work-related programs \\
\hline Decentralization & Extensive and generous services & Protection of workers \\
\hline $\begin{array}{l}\text { Decreasing government } \\
\text { importance }\end{array}$ & Increasing government importance & $\begin{array}{l}\text { Medium important role } \\
\text { of government }\end{array}$ \\
\hline Increasing self responsibility & Minimum income & Means-tested \\
\hline
\end{tabular}

Source: Esping-Andersen (1990).

Resuming, when an aspect of the welfare state meets one of the above criteria, it will fit into the specific welfare type.

\section{Results}

As outlined in the introduction Esping-Andersen's typology is one of the most popular classifications for social systems. The author himself has covered and analyzed the data from 18 OECD countries. Since then many scholars (among them, Stathopoulos, 1996; Fosse, 2011; 
Kam, 2012) have attempted to fit it to other countries, such as Mediterranean countries, postSoviet states and others.

Aiming to place Georgia in this typology and justify/falsify aforementioned theory of "three stable welfare regimes", several aspects of welfare state (pension system, healthcare system, family benefits, labour-market policy) have been analyzed for Georgia.

\section{Georgian Pension System}

The socio-economic collapse associated with the dissolution of the Soviet Union in Georgia was reinforced by the civil war which led to a national macroeconomic crisis, destroying the pension system. Since then the cascade of reforms have started in this sector.

In 1995, the government rejected the existing system of differentiated pensions and replaced it with flat payments. From 2004 the new government improved welfare for the elderly by improving the public pension system and developing a general means-tested social assistance program. After the unrest of November 2007, a political decision was made that scarce resources had to be allocated to increase the general pension for the entire population, which in turn reduced resources for the effective implementation of the means-tested social assistance program (Megrelishvili, 2008). By the beginning of 2011 the Ministry of Finance drafted a new reform proposal. From one perspective, this proposal was designed to fulfill the presidential pledge to increase pensions to 100 USD by 2013, with some differentiated benefits for several categories, such as the disabled and war veterans. From another perspective, a special pension fund would be created to mobilize resources through a $10 \%$ mandatory contribution rate from the population in formal employment, both employers and employees paying $5 \%$ of their salaries and wages. This proposal turned to be extremely unpopular and was rejected (Kvanchilashvili, 2011).

As described above Georgian pension system has been changed for several times, from the minimal flat payment to means-tested one and back, and is still changing after the replacement of government in 2012. According to the criteria described in the methodology section and summarized in Table 1, Georgian pension system by the end of the studied period can be classified as social-democratic.

\section{Healthcare system}

Before 1995 the health delivery system in Georgia was characterized by a structure known in the literature as "Semashko" model, common to all former Soviet Union countries and based on a capillary territorial network of hospitals and polyclinics. It was a centralized delivery system, which grew over time, during the 1970s outnumbering in terms of beds, facilities, physicians, and nurses per capita the health systems of the wealthier Western European countries.

In 1995, the government separated purchasers from providers. Purchasing responsibilities were transferred to the State Medical Insurance Company, Municipal Health Funds and Public Health Department (PHD). At the same time, hospitals and other service providers were transformed into autonomous juridical entities, which would agree on service delivery agreements with the public purchasers and would be reimbursed on a cost-per case basis for services that were part of the basic benefit package (BBP). The main principle of health care reform in 2006 was a transition towards complete marketization of the health care sector: private provision, private purchasing, liberal regulation, and minimum supervision. In 2011 health of certain categories of the population was insured in various private insurance companies within the frameworks of the state health insurance program. The beneficiaries of 
the aforementioned program were: population below the level of poverty, internally displaced people (IDP) settled in compact settlements, beneficiaries of nursing homes, schools and boarding houses, teachers, population residing nearby the occupied territory of the Autonomous Republic of Abkhazia, beneficiaries of community organizations. From January 2013 a new state health insurance program has started targeting the population aged 6-60 years. The government's plan aims to achieve the universal population coverage (Social Service Center 2013).

Respectively Georgian health system can be qualifyed as a liberal one developing towards the social-democretic regime.

\section{Labour-market Policy of Georgia}

Regardless of the collapse of the Soviet Union, employment relationships in Georgia were still regulated by the Soviet Labour Code (1973); changes to the Labour Code were made just in 1997. However, the existing labour legislation still contained soviet elements that were inconsistent with the principles of market economy.

After the "Rose Revolution" (November, 2003), the Georgian government radically changed its view on country's economic development. The political agenda was constructed on the principles and values of liberal economy. Putting all its legislative efforts of minimizing state restrictions and barriers for business activities and promoting free market and industry, Georgian government aimed to establish free liberal economy and attractive climate for foreign investment. In 2006, Georgian parliament adopted a new Labour Code. Soon, international and local organizations, scholars, experts labeled the newly adopted legislation as strictly oriented on employers' priorities and interests (Shvelidze, 2012).

The labour-market policy of Georgia can be definitely qualified as the liberal one.

\section{Family benefits}

In addition to pensions, there are two types of social assistance - category-based and means-tested. Category based social assistance includes family assistance, subsidies on community facilities and IDP benefits. Family assistance is a phasing-out benefit and has been available to the following groups: a) single pensioner; b) pensioner couple; c) disabled child; d) person with 1st category disability; e) families with 7 or more children. This entitlement is limited to those families who applied for assistance before 2007. Subsidies on community facilities are available for 12 categories including war veterans, victims of Soviet repression, etc. The IDP benefit is accessible to all individuals displaced as a result of conflicts in Abkhazia and South Ossetia (1990s and 2008).

Means-tested cash assistance is available for those families who apply to SSA for assistance, are registered in the database of socially vulnerable families and whose meanstesting score is below a certain cut-off point (currently standing at 57 001). Families below the ranking score of 70001 are entitled to free health insurance vouchers which can be exchanged into health insurance (UNICEF, 2012).

According to the criteria described above the family benefits in Georgia are mainly means-tested, and therefore, can be determined as a part of conservative political regime.

The analyzes of these four aspects of welfare state has identified the difficulty of determining the most appropriate place for Georgia in the classification of welfare state proposed by Esping-Andersen. The results of the study are summarized in Table 2. 
Table 2. Different Aspects of Georgian Welfare State

\begin{tabular}{ccccc}
\hline Aspects & Pension System & Healthcare System & Labour-market Policy & Family Benefits \\
\hline Regimes & social-democratic & liberal & liberal & conservative \\
\hline
\end{tabular}

As shown in Table 2, Georgian health and labour-market policy can be qualified as a liberal, pension system - as a social-democratic and family benefits policy - as a conservative. Thus, Georgia can be classified as a hybrid state with instable social policy.

\section{Discussion and conclusion}

Few discussions in modern social science, particularly in the study of welfare states, have attracted as much attention as the work of the Danish sociologist Gøsta Esping-Andersen - "Three World of Welfare State Capitalism". Based on the different variables the author proposed a novel typology of welfare states (liberal, conservative, social-democratic). Since then many scholars have attempted to apply this model to various countries with the aim of identifying their particular welfare status.

The aim of this research was to measure the welfare state of Georgia according to the Esping-Andersen's typology. To answer the research question - "To what extent do the welfare state of Georgia fit into the classification scheme of Esping-Andersen and how does this affect Esping-Andersen's theory of (in)stable welfare states?" - a careful analysis of different aspects of wellbeing was carried out. These aspects are pension and healthcare systems, labour market policy and family benefits. The data collected from reports of the SSA of Georgia, OECD, USAID and research articles showed the diversity of policies in different fields of social care. The research period covered the years from 1991 to 2013.

Georgian pension system turned out to be one of the most changing and reforming social field. According to the characteristics described earlier in the results and the criteria for the pension system classification (see Table 1), Georgian pension system at this moment can be classified as social-democratic.

Based on the main principle of health care reform in 2006, that is a transition towards complete marketization of the health care sector, and also on the universal population coverage health insurance reforms planned in 2013, health system in Georgia can be qualified as a liberal one that is developing towards the social-democratic regime.

Since the Rose Revolution (2003) the new government was oriented on the principles and values of liberal economy, by means of minimizing state restrictions and barriers for business activities and promoting free market and industry.

The family benefits system in Georgia which is mainly category- and means-tested, refers to the conservative political regime.

As discussed above, in two aspects (health and labour market policy) Georgia was determined as a liberal state, but according to two other aspects - social-democratic (pension system) and conservative (family benefits).

The diversity of the results may be due to the fact that Georgia is still a developing country. This statement can be supported by the dynamics of reforms carried in the last 20 years. Policy changes related to the government changes make it difficult to fit it to the specific class or type of welfare state. Thus, it can be considered as a hybrid welfare state.

From all above discussed, the results of the study support the theory of (in)stable welfare state and determine the Georgian state as a country with a hybrid and instable social policy, but the final confirmation (or falsification) of this theory can be achieved after further research (applying the same methodology) carried out after the basic policy reforms new government 
started from 2013 (for example, the social insurance program with universal coverage) are implemented. As the Social Policy is one of the mainstreams of any goverment, the status of welfare state will always be the target for social studies. Invaluable contribution of Espingandersen's typology will be fundamental further, untill any other revolutionary classification is proposed. Likewise the final Georgian welfare status according to the abovementioned typology will be essential for social researchers.

\section{References}

Arts, W., \& Gelissen, J. (2002). Three Worlds of Welfare Capitalism or More? Journal of European Social Policy, 12(2), 137-158.

Bonoli, G. (1997). Classifying welfare states: a two dimensional approach. Journal of Social Policy, 26(3), 351-372.

Burlacu, I. (2007). Welfare state regimes in transition countries: Romania and Moldova compare. Central European University Political Science Journal, 2(3), 302-318.

Clayton, R., \& Pontusson, J. (1998). Welfare-state retrenchment revisited: entitlement cuts, public sector restructuring, and inegalitarian trends in advanced capitalist societies. World Politics, 51(1), 67-98.

Esping-Andersen, G. (1990). The Three Worlds Welfare Capitalism. Cambridge: Polity Press.

Esping-Andersen, G. (1996). After the golden age? Welfare state dilemmas in a global economy. In: G. Esping-Andersen (Ed.), Welfare States in Transition. National Adaptations in Global Economies. London: Sage.

Fenger, HJM. (2007). Welfare regimes in Central and Eastern Europe: incorporating postcommunist countries in a welfare regime typology. Contemporary Issues and Ideas in Social Sciences, 3(2), 1-30.

Ferrera, M. (1996). The "Southern" model of welfare in social Europe. Journal of European Social Policy, 6(1), 17-37.

Fosse, E. (2011). Different welfare states-different policies? An analysis of the substance of national health promotion policies in three european countries. International Journal of Health Services, 41(2), 255-272.

Hague, R., \& Harrop, M. (2007). Comparative Government and Politics: An Introduction. New York: Palgrave MacMillan.

Kam, YW. (2012). The contributions of the health decommodification typologies to the study of the East Asian welfare regime. Social Policy and Administration, 46, 108-128.

London school of Economics (2012). What is social policy? Retrieved from http://www.lse.ac.uk/socialPolicy/aboutUs/introduction.aspx

Shvelidze, Z. (2012). Transition from Soviet to Liberal Labour Law: Labour Standards in Georgia. Retrieved from http://ilera2012.wharton.upenn.edu/RefereedPapers/ShvelidzeZakaria\%20ILERA\%20u pdated.pdf

Social Service Agency (2013). Statistics. Retrieved from http://ssa.gov.ge/index.php?sec_id=610\&lang_id=ENG, 10/01/ 2017

Stathopoulos, P. (1996). Greece: what future the welfare state? In: V. George \& P. TaylorGooby (Eds.), European Welfare Policy; Squaring the Welfare Circle (pp. 136-154). New York: St. Martin's.

UNICEF Georgia \& University of York (2012). The Well-being of Children and Their Families in Georgia. Georgia Welfare Monitoring Survey, Second stage 2011. Retrieved from http://unicef.ge/uploads/WMSFinal_final_Copy_for_web_1_USAID.pdf 
Welfare state (2015). In Encyclopaedia Britannica Online. Retrieved from https://www.britannica.com/topic/welfare-state

Wilensky, H. L. (1974). The Welfare State and Equality: Structural and Ideological Roots of Public Expenditures. Berkeley: University of California Press. 